\title{
O desenvolvimento regional no sudeste do Pará: uma fronteira em consolidação
}

Erisvaldo de Oliveira Alves ${ }^{1}$

Nilton Marques de Oliveira²

\begin{abstract}
Resumo
O artigo buscou tecer considerações sobre o processo de desenvolvimento regional do sudeste do Pará. A metodologia utilizada foi a pesquisa bibliográfica (à guisa da literatura). Os principais resultados apontam, que a região teve na rede dendritica, o surgimento de lugares centrais, e que a partir dos governos militares, teve no modelo de polos de crescimento a sustentação da sua economia regional, apresentando-se atualmente, como uma fronteira em consolidação. Como desafios, tem-se que a região possui aptidão para crescimento sustentado em uma base exportadora, necessitando investir em agregação de valor ao produto regional e internalizar seus benefícios.

Palavras-chave: Desenvolvimento Regional. Sudeste do Pará. Fronteira em Consolidação.

Abstract

This paper aims to weave some considerations about the regional development process of the southeast of Pará State. Was used an exploratory methodological instrument, in light of the literature. The main results point, which the region had at dendritic network, the emergence of central places, and that, since military governments, had the sustainability of its regional economy based on the model of Growth Poles, currently presenting itself as a frontier in consolidation. As challenges, the region has the capacity for sustained growth in an export-based, needing to invest in aggregating value to the regional product and internalizing its benefits.
\end{abstract}

Keywords: Regional Development. Southeast of Pará. Border in Consolidation

\section{Introdução}

A fronteira para Martins (2009), é definida como local onde ocorre o desencontro entre diferentes grupos sociais que juntam e se separam entre a esperança por um pedaço de terra, ou a própria morte. Nesse sentindo, posseiros, indígenas, missionários, colonos e capitalistas tramam luta pela posse da terra. Corroborando com essa ideia, Oliveira, Crestani e Strassburg (2016), apontam que na ocupação das fronteiras agrícolas no Brasil, algumas figuras proeminentes ou grupos sociais destacam-se por desbravarem territórios selvagens e despovoados.

\footnotetext{
${ }^{1}$ Mestre em Desenvolvimento Regional (UFT). http://orcid.org/0000-0002-7608-0858. alvesbm12@gmail.com

${ }^{2}$ Doutor em Desenvolvimento Regional e Agronegócio (UNIOESTE). Professor do Programa de Pós-Graduação em Desenvolvimento Regional da Universidade Federal do Tocantins (UFT). https://orcid.org/0000-0001-6485-314X. niltonmarques@mail.uft.edu.br
} 
A economia da borracha, na Amazônia, embora seja propagada como um período áureo, não enriqueceu a região, pois o excedente do valor produzido localizava-se, inicialmente em Belém e, por fim, nas sedes das grandes firmas internacionais (TAVARES, 2010). Na economia da borracha, o aviamento era a forma de fornecer mercadorias a crédito, na qual o aviador era o seringalista (proprietário) e o aviado o seringueiro.

Mello e Thery (2001), fazem distinção entre o eixo orientado pela navegação fluvial e o eixo criado pelas rodovias, já que os transportes sempre foram determinantes na organização e integração do espaço amazônico. A malha hidroviária fixou a localização das aglomerações nas calhas dos rios durante séculos. Nos últimos anos, porém, a malha rodoviária se consolidou como o novo padrão de localização das cidades, o da terra firme.

Considerando o momento após 1960, tem-se que as terras à margem da rodovia são valorizadas, estruturando-se um mercado de venda de terras, ocorre um intenso fluxo migratório para o sudeste do Pará, na esperança de encontrar terra boa e farta para cultivar. Os produtos industrializados do Sul e Sudeste chegam pela rodovia, aumentando a concorrência e desestruturando a organização do mercado local (MOURA; PELEJA; FARIA, 2011).

Segundo Congilio e Ikeda (2014), o Programa Grande Carajás (PGC), tornou-se um projeto de exploração pela VALE S.A. sendo que, a área onde se desenvolve é considerada a mais rica em

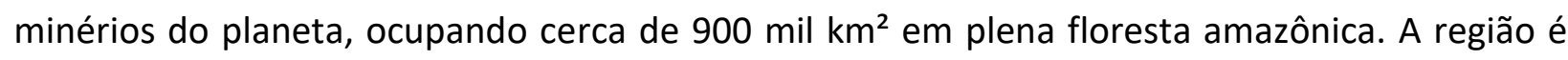
cortada pelos rios Xingu, Tocantins e Araguaia. Além do minério de ferro, são explorados manganês, cobre, níquel, ouro, bauxita e cassiterita.

No entanto, o sudeste do Pará apresenta-se atualmente em um processo, que Becker (2009) chama de "fronteira em consolidação", no qual a migração da população é intrarregional e não inter-regional como no passado, apresenta atividades agropecuárias e de extração mineral integradas ao tecido produtivo nacional e aumento crescente da produtividade e lucratividade das atividades econômicas, em detrimento da conservação ambiental.

Isto posto, este artigo está estruturado da seguinte forma, além da introdução, no segundo capítulo apresenta-se teorias do desenvolvimento regional utilizadas na leitura e considerações sobre a região, no terceiro, discute-se como ocorreu o processo de ocupação da região, com destaque para as principais frentes de expansão e fatores de influência na consolidação do processo e, por fim, as considerações finais. 


\section{Teorias do desenvolvimento regional}

Ao considerar as características do sudeste do Pará, optou-se por utilizar elementos das teorias de aglomeração, focando na Teoria dos Polos de Crescimento e; das teorias de localização, com foco na Teoria dos Lugares Centrais. Complementando a análise, tem-se a Teoria da Base de Exportações, que foi construída sobre o direcionamento dos ensinamentos da corrente locacional.

\subsection{A teoria dos lugares centrais}

O geógrafo Walter Christaller (1966) elaborou a Teoria dos Lugares Centrais, uma teoria geométrica do espaço onde são representados os polígonos espaciais, estabelecendo hierarquia entre as cidades. A teoria propõe a centralidade como um princípio de ordem espacial, o autor baseou-se em estudos sobre a Alemanha Meridional, utilizando um índice calculado sobre a utilização do telefone, procurando estabelecer a área de influência das cidades de acordo com o seu porte e o nível de demanda por produtos, essa teoria provocou, nas décadas de 1960 e 1970, o florescimento da chamada geografia quantitativa e a utilização dos métodos matemáticoestatísticos (VASCONCELOS, 2009).

Já Lopes (1984) explica que o modelo de Christaller utiliza certos pressupostos e hipóteses quais sejam: O primeiro seria que a população distribui-se de forma homogênea no espaço, em um padrão triangular com distancias iguais entre os compradores mais próximos; O segundo pressuposto é que a oferta localiza-se em pontos, os chamados lugares centrais; Em terceiro, tem-se que a procura pelos bens e serviços nos lugares centrais é assegurada pela população ali residente e pelos residentes da chamada área complementar; A quarta hipótese da teoria é que existe variação na ordem de importância dos bens e serviços de acordo com a sua frequência de necessidade, sendo os de ordem mais elevada os que raramente são procurados; Em quinto, tem-se que a ordem de importância dos bens e serviços oferecidos em um determinado centro está relacionada à ordem de importância do próprio centro; Por último, considera que o centro que desempenhe função de ordem superior, certamente desempenha as funções de ordem inferior.

Para Christaller (1966) a conexão entre os lugares centrais e a região complementar depende de algumas características dessas regiões, como: tamanho da área, a paisagem e meios 
de transporte, além das suas características naturais - a fertilidade do solo e a presença de minerais e, se toda a região ou apenas uma parte dela pertence ao lugar central. Argumenta que há um raio no qual se estende o mercado, definido pelo alcance do bem ou serviço, variando a distância com o custo, preferencias, qualidade, etc.

A centralidade da área seria definida pela importância do bem ofertado, sendo assim, Christaller define o alcance máximo, que é a área de abrangência em que a localidade exerce seu poder de atração sobre os consumidores e o alcance mínimo, que é a área no entorno do lugar central onde há pessoas com renda para consumir. E existiriam diversos tipos de centros, aqueles que abastecem áreas reduzidas com bens e serviços limitados, até os centros de ordem maior que podem chegar a suprir, toda sua área de abrangência, que seriam os centros de ordem máxima (BRITO, 2009).

\subsection{Os polos de crescimento}

Segundo Lima e Simões (2010), Perroux descarta o conceito de espaço euclidiano e utiliza o conceito de espaço abstrato, entendido como mais adequado para analisar a economia. Coexistindo tantos espaços econômicos quantos fossem os fenômenos econômicos estudados. Assim, a teoria dos polos de crescimento apresenta seus pressupostos: o espaço definido como conteúdo de um conjunto das relações entre a empresa, fornecedores e compradores; o espaço definido como campo de forças e o espaço definido como conjunto homogêneo.

A análise do espaço econômico abstrato define que decisões do governo afetam de formas e intensidades diferentes os subespaços (estados, regiões, municípios) dada sua heterogeneidade. Esses subsistemas são hierarquizados em função da dependência das decisões do governo central, das multinacionais e dos efeitos advindos dessas decisões do poder central, por tanto, caso esses elos estejam frouxamente relacionados, tem-se a constituição de subsistemas relativamente isolados. Por isso, Perroux preocupa-se com a medição da intensidade dos elos dessa cadeia, onde uma medida importante é a proximidade ou distância entre essas subáreas, já que quanto mais próximos dois pontos estiverem, maior será seu relacionamento, de forma geral, um subespaço dominante exerce maior influência nos subespaços próximos (FERREIRA, 1991).

O ponto de sustentação da teoria está na definição de polo de desenvolvimento como locais capazes de aumentar o produto, modificar as estruturas, gerar inovações tecnológicas e 
provocar ou favorecer o progresso econômico da região, ou conforme Lopes (1984, p.37) “A região polarizada pode ser definida como uma área na qual as relações econômicas internas são mais intensas do que as estabelecidas entre regiões exteriores a ela". O conceito de indústria motriz, definida como a que mais cedo do que as outras se desenvolve de forma moderna, e cujas taxas de crescimento são mais elevadas do que a taxa média de crescimento do conjunto da economia, durante determinado período, está intimamente ligado ao desenvolvimento da região. Da mesma forma, o polo de desenvolvimento seria uma unidade econômica motriz ou conjunto de várias unidades que exercem efeitos de expansão sobre outras com as quais se relaciona (OLIVEIRA; LIMA, 2003; CAVALCANTE, 2008; LIMA; SIMÕES, 2010).

Segundo Madureira (2015), Alves de Jesus e Spinola (2015), Perroux aborda três elementos de análise sobre os Polos de Crescimento, o primeiro elemento analisado é; a indústria-chave, entendida como a indústria que ao aumentar sua produção, eleva a produção da indústria e/ou indústrias vizinhas, essa indústria é chamada de motriz e as demais de indústrias movidas. O segundo elemento é; o regime não concorrencial do complexo, que torna o sistema instável, pois tende a gerar uma combinação de forças oligopolistas. O terceiro elemento abordado em Perroux é; o efeito da aglomeração territorial, esse elemento funde os dois elementos discutidos anteriormente. "Num polo industrial complexo geograficamente concentrado e em crescimento, registram-se efeitos de intensificação das atividades econômicas devidos à proximidade e aos contactos humanos" (PERROUX, 1967 p. 174).

\subsection{A teoria da base de exportação}

Dallabrida (2017) aponta que até a década de 1950 explicações sobre desenvolvimento regional confundiam-se com as explicações sobre desenvolvimento das nações e, que a teoria da base de exportações é elaborada nesse período, constatando-se que muitas regiões tinham se desenvolvido sem seguir a receita das fases ou etapismo ${ }^{3}$, algumas regiões canadenses e americanas tiveram seus impulsos para o crescimento através das exportações lucrativas de recursos naturais. Nesse sentido, a teoria passou a ser considerada para explicar quais regiões

\footnotetext{
${ }^{3}$ Refere-se a ideia de classificar os sistemas econômicos históricos, onde as fases evolutivas seriam reflexo da complexidade alcançada pela divisão do trabalho, no qual relaciona-se o investimento e o consumo dos setores primários para o terciário, passando pela fase industrial. Autores como Rostow (1974) identificaram as condições que desencadeariam a transição das regiões para as fases mais avançadas.
} 
estariam mais propícias ao crescimento através de exportações e quais fatores determinam o ritmo desse crescimento. Para Piffer (2009); Madureira (2015) e Oliveira (2015), o pioneirismo sobre a teoria da Base de Exportações, deve-se a trabalhos como North (1977a) e North (1977b), onde explica como ocorre o processo de desenvolvimento econômico via atividades produtivas.

Base de exportação, designa coletivamente os produtos exportáveis de uma região. 0 desenvolvimento desses produtos de exportação representam uma vantagem comparativa nos custos de produção, à medida que as regiões crescem em torno desta base são geradas economias externas, que estimulam a competitividade dos produtos exportáveis, aumentando a renda da área e definindo a dinâmica das atividades locais (OLIVEIRA; LIMA, 2003; LIMA; SIMÕES, 2010). Essa teoria pode ser dividida em duas partes; a primeira é a verificação de quais fatores levam uma região a exportar, nesse caso, destaca-se o papel dos princípios da teoria da localização, ou seja, a capacidade de integração ao mercado externo da região dependeria da sua localização e da existência do recurso natural em qualidade e quantidade procurada; a segunda é a análise de quais regiões, após integrarem-se ao mercado externo, são capazes de desenvolver um processo de crescimento duradouro e autossustentado, nesse caso, a analise recai sobre a capacidade de difusão dos efeitos do aumento da renda obtido pela exportação dos produtos base, para outros setores da economia (SCHWARTZMAN, 1977).

Na leitura de Piffer (2009); Lins, Lima e Gatto (2012), tem-se que existe um foco nas chamadas "regiões novas", ou seja, áreas cujo objetivo básico era explorar a terra e seus recursos com o fim de produzir bens que pudessem ser comercializados externamente à região, e que se transformariam em renda monetária, baseada em poucos produtos de exportação. Nesses casos, todo o restante do setor secundário e terciário é passivo, já que se destina apenas a atender às necessidades do consumo local.

Douglass North em seu trabalho intitulado Agriculture in regional economic growth, afirma que, a expansão de um setor base é condição necessária para o crescimento regional, mas não é uma condição suficiente. A dotação inicial da região determina seus bens exportáveis, tendo como exemplo um produto da lavoura e, caso a vantagem comparativa desse bem seja muito superior a qualquer outro bem, ter-se-á uma concentração de recursos na sua produção, porém, decorre da natureza tecnológica da função de produção que, se o produto de exportação for do tipo extensivo, o qual o autor define como relativamente intensivo em trabalho e com 
significativos rendimentos decrescentes de escala ${ }^{4}$, haverá uma tendência ao surgimento de uma distribuição de renda desigual. Nesse caso, ter-se-ia a maioria da população dedicando suas rendas para necessidades simples como alimentação, no outro extremo, tem-se os proprietários das lavouras consumindo a maior parte de sua renda com bens de consumo de luxo, importados, o que definiria uma situação na qual existiria pouco encorajamento de atividades econômicas domésticas (NORTH, 1977a).

\section{Processo de ocupação da região sudeste do Pará}

A região sudeste do Pará, passou por vários processos de dinâmica social e econômica durante sua história. Santos (1980), Velho (2009), Tojal e Ricci (2009), apontam que a região esteve sujeita a influência de polos e frentes de expansão diversos. Por ser um ponto entre Amazônia e Nordeste, tornou-se local de encontro de povoamentos oriundos do Pará, de Goiás e do Maranhão.

\subsection{As frentes de expansão na região sudeste do Pará}

As incursões iniciais, podem ser entendidas como intermitentes e de poucas consequências reais para a região. Em 1721 tem-se a primeira grande exploração no Itacaiúnas. No entanto, a navegação no rio foi prejudicada pelo receio da Coroa de que se tornasse uma rota de desvio dos metais preciosos, oriundos da mineração no norte goiano, ainda assim, houve efeitos indiretos sobre o sudeste do Pará. No caso da agricultura, representada pela frente agrícola maranhense, chegou a avançar na foz do rio Itacaiúnas, mas restringiu-se a esta (VELHO, 2009). Os principais efeitos da frente mineradora, sobre o sudeste do Pará, foram negativos, já que a proibição da navegação pelo rio Tocantins, manteve o isolamento da região, pois eram os rios os principais eixos de transporte da rede dendrítica.

\footnotetext{
Além das decisões administrativas na tentativa de isolar o Norte de Goiás, como a proibição da navegação fluvial pelo Tocantins, que afastava a região das outras capitanias - Grão-Pará e Maranhão -, e a interdição do acesso pelas picadas vindas do Nordeste - Bahia, Piauí -, o norte goiano sofreu ainda os ataques da população autóctone durante todo o período colonial (PARENTE, 2003, p. 49)
}

\footnotetext{
4 "Ocorre quando todos os fatores de produção crescem numa mesma proporção, e a produção cresce numa proporção menor" (Vasconcellos, 2006, p. 119).
} 
Uma outra frente de expansão que teve efeitos indiretos no sudeste do Pará foi a frente pecuarista $^{5}$, a corrente de origem baiana cruza o norte goiano até chegar ao que Velho $(2009, \mathrm{p}$. 25) chama de "últimos campos naturais" os campos da Barreira, na bacia do Najá, do Arraias e do Pau d'Arco, no território paraense, o que originou o município de Conceição do Araguaia. A frente pecuarista caracterizava-se por ser inseparável dos campos naturais, fatores como isolamento e baixa produtividade implicavam em baixos investimentos, o que, por sua vez, perpetuavam suas características, numa espécie de círculo vicioso. Uma outra frente desceu até o Itacaiúnas, seguindo na direção norte. Esses movimentos são vistos pelo Pará como oportunidade de definições sobre os limites geográficos litigiosos entre os estados do Pará, Goiás e Maranhão (SANTOS, 1980).

\begin{abstract}
Como ponto inicial da colonização, donde partiriam em busca dos campos, fundam, então, após uma experiência, inicial frustrada junto à foz do Itacaiúnas, o Burgo Agrícola do Itacaiúnas, na praia dos Quindangues, à margem esquerda do Tocantins, $8 \mathrm{~km}$ a jusante da foz do Itacaiúnas, em sítio alto e livre de enchentes. Tratava-se de trecho do Tocantins ainda praticamente desabitado, a não ser, cerca de 25 quilômetros abaixo, na Praia da Rainha e no Lago Vermelho, por alguns maranhenses e goianos recém estabelecidos, realizando um pequeno comércio de caça, peixe salgado e produtos de roça, que daria origem a Itupiranga (VELHO, 2009, p. 26).
\end{abstract}

Em 1809 foi criada a comarca do Norte, inicialmente, tentou-se, a instalação, próximo ao atual município de Marabá, porém, devido ao seu isolamento, transferiu-se a sede da comarca para a vila de Palma, mais para o sul em Goiás. No Itacaiúnas, mantem-se um destacamento de tropas que se transfere posteriormente para a confluência do Araguaia com o Tocantins, onde hoje se encontra São João do Araguaia (VELHO, 2009).

Sobre a economia da borracha, Velho (2009) argumenta que faz parte de um grupo de drogas do sertão ${ }^{6}$, e que o seu ciclo ocorreu em um contexto em que a Amazônia se encontrava a margem do Brasil, sendo que permaneceu nessa situação por séculos. As frentes de expansão definem relações sociais com temporalidades diferentes, ou seja, “Entre a fronteira demográfica

\footnotetext{
${ }^{5}$ A frente maranhense ocupou o Sertão dos Pastos Bons, de onde se espalhou fazendas de gado por toda a região. Devido a abundância de terras, baixa produtividade e pequena mão-de-obra, essa frente fecha-se em si mesma, como atividade de subsistência e marginalizada, porém detentora de maior autonomia em relação à plantation (VELHO, 2009).

${ }^{6}$ Denominação dada a um grupo de produtos obtidos por atividade extrativista da floresta amazônica entre estas drogas estavam (urucum, guaraná, castanha-do-pará, algodão, fumo, açúcar, mandioca, dentre outros).
} 
e a fronteira econômica está à frente de expansão, isto é, a frente da população não incluída na fronteira econômica" (MARTINS, 1996, p. 31).

A borracha faz parte de uma frente de expansão denominada de extração livre, que desde a década de 20 do século XIX registrava-se exportações de borracha, intensificando-se na segunda metade daquele século. Esse aumento de demanda é explicado, nas palavras de Furtado (2005) pela expansão, no início do século XX, da procura de borracha como matéria prima para as economias industrializadas, empregada na indústria de veículos e de motores a combustão interna, por ser a borracha um produto extrativo, onde o estoque de árvores concentrava-se na bacia amazônica, o aumento de produtividade para atender a demanda crescente era extremamente difícil.

Foi a partir do século XIX, que o padrão de ordenamento territorial de caráter dendrítico ${ }^{7}$, passou a se alterar. Os rios, ainda que permanecessem como principais vias de circulação, começaram a dividir espaço com as poucas ferrovias. A alteração desse padrão começou a ocorrer a partir do período de produção da borracha na Amazônia. As ferrovias, como a BelémBragança, a Madeira Mamoré e a Estrada de Ferro do Tocantins, representavam, uma nova ordem espacial de caráter mais reticular, com a ocupação da terra firme e a presença de colônias agrícolas (TRINDADE JÚNIOR, 2015).

Foi no período da borracha que se produziu na região amazônica a economia de aviamento, assim esquematizada por Santos (1980). No aviamento, "A" chama-se aviador e "B" chama-se aviado, A fornece a B uma quantidade de mercadoria (bens de consumo e instrumentos de trabalho), ficando B obrigado a resgatar a dívida com produtos agrícolas ou extrativos da própria safra. Havendo saldo credor, B recebe em dinheiro. Se o saldo for devedor, B fica em débito até a safra subsequente. Tem-se dessa maneira um esquema geral do aviamento. No entanto, sua constituição, é mais complexa. Assim, o aviado B pode perfeitamente tornar-se aviador de C e C, que é aviado, pode refinanciar a D, tornando-se aviador e assim, sucessivamente.

Na Amazônia, a indústria extrativista esteve conjuminada ao capital estrangeiro. Os seringalistas da borracha estavam vinculados às casas aviadoras, e dependiam delas para o financiamento. As casas aviadoras, por sua vez, funcionavam em razão da

\footnotetext{
${ }^{7}$ Sobre esse ordenamento territorial, é fácil associá-lo ao formato de uma árvore, cujo tronco é o rio principal, e os galhos e ramos, os diversos afluentes e subafluentes.Com as seguintes características: Existência de uma cidade que se destaca pela sua importância, localização e grandeza; Grande número de cidades pequenas com funções parecidas e situadas próximas aos locais de produção ou em espaços estratégicos para a distribuição das mercadorias; Poucos núcleos de povoamento de porte intermediário e; Concentração das riquezas na cidade principal e em espaços externos à região (CORRÊA, 1987).
} 
produção de borracha para a comercialização no exterior, de onde provinham os recursos. Apesar da dependência desse mercado, os patrões exerciam o seu poder nos seringais e interferiam no modo de produção, utilizando métodos exploratórios para subjugar os trabalhadores (RODRIGUES; TRINDADE; BITENCOURT, 2016).

Essa situação apresenta-se como a descrita por Farage (2009), ao discutir as ideias de Martins (2009), afirmando que nas experiências de "Frentes de Expansão e Frentes Pioneiras", buscou-se a expansão territorial como forma de garantir a reprodução do capitalismo, recriando ações e atividades típicas do processo de acumulação primitiva do capital.

Segundo Moura, Peleja e Faria (2011), até 1960, predominava a terra pública na região amazônica, havia apenas $2 \%$ de terras tituladas como privadas, não se discutia a questão ambiental e não havia um mercado de terras estruturado, já que a região era isolada do resto do país. A economia tinha como fundamento o extrativismo animal, vegetal e mineral.

Sobre a frente extrativista da castanha, não se trata de um novo período, já que em relação a borracha tem-se atividades econômicas do mesmo tipo, o que ocorre é um ajuste pós momento de crise, no qual foram mantidas as relações de trabalho (BRITO, 2009). A extração da castanha sempre esteve presente no território amazônico. A queda dos preços da borracha, e a consequente decadência dessa droga do sertão, levou ao ressurgimento da extração da castanha, especialmente na região do médio Tocantins. A extração da borracha preparou o caminho para a extração da castanha e, Marabá destaca-se como centro dessa produção, em detrimento, particularmente, do baixo Tocantins ${ }^{8}$ (Santos, 1980). “O transporte da castanha pelo Tocantins, tal como anteriormente o da borracha, realizava-se em geral por conta dos comerciantes de Marabá, pelo menos até Alcobaça (a qual, após 1943, ao ser desmembrada de Baião, passará a denominar-se Tucuruí)" (VELHO, 2009, p. 49).

Aos poucos, fortalece-se uma agricultura de terra firme, e obscurece-se a pequena agricultura de várzea, junte-se a isto o alto incremento demográfico que a área do Itacaíunas teve na década de 1950. Afastando-se do rio em busca de terras melhores e desocupadas, temse um avanço significativo na região de São João do Araguaia. Nesse processo, surgem os aglomerados, que apesar de terem a vantagem de serem menos isolados, exigiam regras de convivências, um exemplo é a criação de porcos, já que esses animais tendem a invadir as roças,

\footnotetext{
${ }^{8}$ O Baixo Tocantins, é formado pelos rios Moju, Pará e Tocantins. Os municípios de: Abaetetuba, Igarapé Mirim, Limoeiro do Ajuru, Cametá, Mocajuba, Baião e Oeiras do Pará; compõem a região, que sofre os impactos da barragem de Tucuruí. Desse conjunto, só Oeiras do Pará não é banhado pelo Tocantins, e sim pelo Rio Pará (ALMEIDA, 2010).
} 
o que pode gerar conflito entre os moradores. Quando um aglomerado demonstrava que tinha condições de se expandir, transformava-se em local de comercialização, passando a atrair mais moradores, movimento que era intensificado quando, passava a oferecer instrução escolar para as crianças, nesse ponto, tem-se um poderoso fator de polarização, podendo chegar a esvaziar os aglomerados menores. Essa frente apresenta um caráter novo, pois até então, os movimentos em toda a área da Amazônia eram ditados pelos cursos dos rios, os grandes eixos fluviais, no entanto, essa frente agrícola busca o interior, as áreas desocupadas (VELHO, 2009).

A abertura da Belém-Brasília é parte importante do processo de crescimento econômico, coincidindo com o aumento da pressão gerada pela frente agrícola. Outro reforço foi a política de créditos inaugurada em 1960 pelo Banco do Brasil, destinada ao pequeno produtor rural e entendida como liberal, pois provas simples de ocupação da terra eram aceitas para a liberação do financiamento, em 1964 este banco abre uma agência no município de Marabá. Com isso, um forte movimento de legalização de terras ocorre em municípios como São João do Araguaia e São Domingos do Araguaia (VELHO, 2009).

Sobre a PA-70, tem-se que foi aberta em caráter precário em 1969, apresentando-se como novo eixo de ocupação na margem direita do Tocantins, a construção do ramal passou a ser considerado logo após a construção da Belém-Brasília, que ficava afastada de Marabá "De fato, a estrada não vai até Marabá, pois cruza o rio cerca de $15 \mathrm{~km}$ acima, numa localidade chamada São Félix, que em 1965 possuía apenas três casas de moradores, e para a qual o Censo de 1970 registrará 297 casas e 1.461 habitantes" (VELHO, 2009, p. 131). Esse exemplo demonstra uma das principais características das fronteiras, o rápido e desordenado, crescimento demográfico.

Possuir ligação com a rodovia Belém-Brasília, significou ligar-se a todo o país, por ela penetraram, além dos agricultores maranhenses, fazendeiros baianos, mineiros e capixabas. Há também, representantes da camada média de origem urbana, trazidos pela possibilidade de terras desocupadas. Contam-se algumas firmas gaúchas, paranaenses e também norteamericanas, empenhadas, até então, na exploração da madeira, em áreas ainda próximo à Belém-Brasília. Um exemplo de como o transporte rodoviário alterou a dinâmica local é citado por (VELHO, 2009, p. 141).

Até 1969 uma viagem de São Domingos até Marabá exigia percorrer a estrada de São Domingos até Apinagés a pé, montado ou pegando um lugar num jipe ou caminhão eventual. Se conseguisse um transporte por rio em Apinagés até às 15h, com cerca de 
mais 3 a 4 horas de transporte por rio chegava-se a Marabá (na volta a subida levava de 8 a 9 horas). Depois das 15h, já não era possível navegar, pois o sol se põe exatamente na direção do curso do rio, dificultando a visão dos pilotos e tornando a navegação muito perigosa nas corredeiras e canais. Quem não conseguisse transporte até essa hora, o que era comum, tinha de pernoitar numa palhoça na beira e aguardar o dia seguinte. A partir de 1969, com a estrada Marabá-São João, passou-se a realizar a viagem em 3 horas de jipe ou 6 horas de lotação. A partir de outubro de 1971, com a Transamazônica, a viagem de São Domingos a Marabá reduziu-se a um trecho de $56 \mathrm{~km}$, percorridos em 1 hora de ônibus.

A partir dos anos de 1980, boa parte da dinâmica econômica da região dos Carajás e, principalmente, do município de Marabá, se deve à Companhia Vale do Rio Doce, em virtude disso, a população passou de 24.474 hab. em 1970, para 233.669 hab. em 2010 (característica das fronteiras). Marabá destaca-se como uma base logística da empresa Vale, possuindo papel importante como entroncamento rodoferroviário, formando uma região de integração, constituída pelos municípios de Marabá, Bom Jesus do Tocantins, Brejo Grande do Araguaia, Canaã dos Carajás, Curionópolis, Eldorado dos Carajás, Parauapebas, Palestina do Pará, Piçarra, São Domingos do Araguaia, São Geraldo do Araguaia e São João do Araguaia (SPOSITO; ELIAS; SOARES, 2016).

A exploração de minério, que utiliza como base o carvão vegetal, intensificou o desmatamento da região. Grandes indústrias mineradoras transferiram-se para a Amazônia no fim da década de 1980, com destaque para as que produzem bauxita, alumina e ferro-gusa. Apesar da aparência de indústria moderna, ela reproduz o modelo agroexportador de semielaborados e produtos in natura. Na Amazônia a modernização não disseminou benefícios, mas sim, gerou concentração de riqueza e devastação da natureza valendo-se de força de trabalho informal e ilegal (MOURA; PELEJA; FARIA, 2011; CONGILIO; IKEDA, 2014).

Falando sobre o garimpo na região, Garrido Filha, Costa e Ribeiro (1988) e Brito (2009) afirmam que o mais importante foi o de Serra Pelada, que recebeu esse nome devido ao tipo de cobertura vegetal da área, formada por campos rupestres, mas o verdadeiro nome do local é Morro da Babilônia. Essa atividade implicou no surgimento de alguns núcleos urbanos como Curionópolis.

Becker $(2005,2009)$ explica que nos anos de 1970, o que sustentou o avanço da fronteira foram os incentivos fiscais e a migração induzida pelo governo federal. A autora localiza a principal frente de expansão, atualmente no sudeste do Pará, como sendo de São Felix do Xingu em direção ao rio Iriri. 
Em 1964 o governo militar, ao identificar pontos de estrangulamento na economia, apresentou como solução o Programa de Ação Econômica do Governo (PAEG), que objetivava retomar o crescimento nacional através de um arcabouço institucional para fortalecer tanto o mercado de ações como a política de financiamento (Brito, 2009). Já Villarino (2016), caracterizando além do PAEG o Plano Trienal de Desenvolvimento Econômico e Social, lançado dois anos antes, afirma que o PAEG trouxe como novidade a noção de mercado enquanto "sistema de preços", por outro lado há no plano um silenciamento das expressões "estrutura, formação de capital e endividamento externo", o autor afirma que a principal diferença entre os dois planos é que enquanto o Trienal define o estado como responsável pela seleção qualitativa de investimentos corretivos, o PAEG elege o estado como responsável por manter e incentivar um nível quantitativo de investimentos agregados.

Segundo Brito (2009) com a implantação do II Plano Nacional de Desenvolvimento (II PND), iniciou-se no país uma desconcentração industrial com financiamento e construção de infraestrutura básica, ocorrendo uma capacitação de áreas denominadas "atrasadas" as quais passaram a gerar novos investimentos, notadamente relacionados à modernização da agropecuária, construção de parques industriais e em pesquisa e desenvolvimento (P\&D). Dentre os grandes projetos nacionais que impactaram a região sudeste do Pará, o autor destaca a construção do Complexo Carajás-Ferrovia do Aço. "No I e II Plano Nacional de Desenvolvimento (PND), entre 1972 e 1978, o Estado, por meio de ações centralizadas, encorajou a ocupação da Amazônia Legal e do Cerrado oferecendo terras e créditos para os produtores rurais oriundos de outras regiões do país" (OLIVEIRA, 2017, p. 16).

Falando sobre o Programa para a Integração Nacional (PIN), Kohlhepp (2002) ensina que, o programa data da primeira metade dos anos 1970 e foi baseado no conceito de planejamento de eixos de desenvolvimento, colocado em prática com a construção de estradas de longa distância, como a Transamazônica. As estradas pioneiras serviram de roteiros de migração para a Amazônia e foram planejadas para o estabelecimento de áreas de atividades econômicas na forma dos chamados "corredores de desenvolvimento". Comentando sobre a importância do PIN, Brito (2009) faz constar que o programa direcionou recursos para a construção da BR 230 (Transamazônica), principal rodovia da porção norte no sentido leste/oeste, beneficiando algumas cidades dentre elas Marabá. Ainda segundo o autor, o objetivo principal dessa rodovia era deslocar nordestinos (mão-de-obra) para ocupar a faixa ao longo da rodovia, através de assentamentos planejados. Ainda em um processo de expansão da fronteira. 
Em 1974 foi estabelecido o Poloamazônia, com um viés em programas agropecuários e minerais, distribuiu polos de crescimento, dos quais tem-se a instalação da infraestrutura básica para a área da reserva mineral de ferro da Serra dos Carajás (Brito, 2009). Nessa segunda fase, as estratégias de planejamento regional na Amazônia concentraram-se no conceito de polos de crescimento. Os polos foram baseados em pontos focais setoriais, como extração de recursos minerais ou áreas de criação de gado com possível processo industrial (KOHLHEPP, 2002).

Sobre o Programa Grande Carajás (PGC), que foi o grande projeto de exploração mineral na região sudeste do Pará, Kohlhepp (2002) afirma que as decisões eram tomadas sem qualquer coordenação com as respectivas autoridades regionais ou locais, nem mesmo a SUDAM

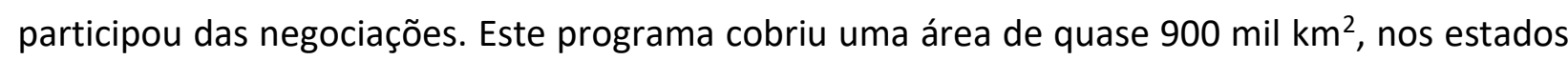
do Pará e do Maranhão. O programa demonstrou forte dependência das condições do mercado mundial. Além disso, a construção de estradas, a ferrovia da mineração Carajás, a construção da usina hidrelétrica de Tucuruí e a larga rede de sistemas de transmissão, contribuíram para a sobreposição de novas estruturas espaciais e um novo surto de devastação das florestas, associada à produção de carvão vegetal, fazendo aumentar as disparidades socioeconômicas intrarregionais e a desintegração regional.

Para Congilio e Ikeda (2014) o governo brasileiro tem financiado empresas e infraestruturas para megaprojetos de expansão de fronteira no sudeste paraense. Os autores destacam ainda que ocorre um espalhamento de relações de trabalho deterioradas da VALE para os demais setores produtivos na região e citam os projetos associados ao Programa Grande Carajás como a construção de estradas e da ferrovia da mineração Carajás, construção do porto de Itaqui, que liga a ferrovia que sai de Parauapebas ao transporte marítimo para exportação do ferro e a construção da usina hidrelétrica de Tucuruí, todos teriam contribuído para a formação de novas estruturas espaciais.

Já o III PND (1979-1985), não teve a mesma infiltração de suas ações na região como os planos anteriores, ainda que tivesse em seu escopo a intenção de prosseguir com as ações regionalizadas, a instabilidade política e econômica, que acometeu os anos 1980, obrigou o Estado a dedicar-se à solucionar os problemas macroeconômicos, como a inflação e o pagamento da dívida externa, deixando de lado as questões relativas às políticas regionais (OLIVEIRA, 2017). 


\subsection{Fatores de influência no processo de consolidação da fronteira}

O sudeste paraense responde por $32,0 \%$ das rodovias estaduais e por $34,5 \%$ das rodovias federais do Estado, apresentando boa cobertura de estradas, de forma que as cidades mais importantes da região estão conectadas por estradas que as ligam entre si e aos grandes centros mais próximos (Belém, São Luís, Goiânia, etc), como entraves, tem-se problemas na manutenção da malha e necessidade de ampliação. Sobre o sistema de transporte aéreo, a região conta com dois dos seis principais aeroportos do estado (nos municípios de Marabá e Parauapebas), só o aeroporto João Correa da Costa, em Marabá, teve o maior movimento operacional dentre os aeroportos do estado, entre 2003 e 2009, entre movimento de passageiros e de carga transportada, houve um incremento de $606,8 \%$ e $396,9 \%$, respectivamente no período (SANTOS, 2017).

A malha ferroviária de maior importância econômica da região Norte é a EFC, cujo traçado de 892 km corta, parte dos estados do Maranhão e do Pará. A ferrovia transporta o minério de ferro produzido pelo Projeto Ferro Carajás e de outros projetos da Vale. Sobre hidrovias, existe a perspectiva de navegabilidade até certo calado de navios da bacia do Araguaia-Tocantins, a partir da foz do Tocantins até a congruência com o rio Araguaia e, desta, até Barra das Garças em Mato Grosso. Um trecho já está sendo utilizado partindo de Nova Xavantina (Mato Grosso) e São Geraldo do Araguaia no sudeste do Pará (SANTOS, 2017).

A rede de transporte montada em volta da região, principalmente nas proximidades de Marabá, coloca esse município em melhores condições de centralidade. Considerando que os movimentos populacionais, atualmente, deslocam-se dentro da região com crescimento basicamente vegetativo (relativo à taxa de natalidade) e que as atividades econômicas se desenvolvem em sua maioria em áreas já desmatadas (Becker, 2009), é possível considerar a região como uma fronteira em processo de consolidação, e nesse caso, o avanço tecnológico (para o aumento produtivo), a infraestrutura (principalmente de transporte) e o acesso a informação, são elementos essenciais do processo.

Na região destaca-se as atividades de mineração da Vale, essa indústria classifica-se, dentro dos conceitos definidos na Teoria dos Polos de Crescimento, como indústria Motriz "As indústrias motrizes são indústrias novas que possuem também novas tecnologias, contudo nada impede que as indústrias motrizes sejam de setores maduros, já implantados" (ALVES DE JESUS; SPINOLA, 2015, p. 939). 
Porém, o processo de polarização econômica na região não é tão simples, exemplo é a situação exposta por Kohlhepp (2002), para o qual o Programa Polamazônia, interpretou de forma equivocada o conceito dos polos de crescimento e como resultado gerou o aumento das disparidades do desenvolvimento inter e intraregional. Com isso, a "periferia" tornou-se ainda mais dependente do "centro", em nível nacional e internacional. Certo é que, alguns desafios devem ser superados, como exemplifica Palheta et al (2017), detalhando que o debate que associa mineração ao desenvolvimento, colocando no eixo central da pauta política reivindicações relacionadas a royalties, além de impostos e verticalização da produção, esgotouse mais rapidamente do que as jazidas, além de se mostrar como ideologia que omite os dois elementos que devem ser colocados na centralidade: o controle do território e a democratização da riqueza mineral.

Existem lugares centrais na região, devido a vantagens comparativas que vão desde constatações geográficas de rede dendrítica até rede de transportes construídas em virtude de polos de crescimento, com industrias motrizes tradicionais, no entanto, a grande maioria dos municípios da região possui aptidão para o crescimento e desenvolvimento via base exportadora, e essa seria a principal dinâmica capaz de manter um crescimento econômico a longo prazo.

Tratando de como é possível o desenvolvimento regional a partir de uma base exportadora commodity, North (1977b) sustenta que não há necessidade de industrialização da região (em sentido estrito), pelo simples fato de ser difícil chegar a esse "estágio" dada a dificuldade de canalizar recursos para promover investimentos de capital em grande escala, buscando melhora nos transportes, a necessidade de superar a dificuldade de promover uma divisão geográfica do trabalho e, talvez o principal limitador, seja o fato de que a tecnologia industrial é estranha à região. Porém, o que em nenhum momento a Teoria nega é a necessidade de agregar valor ao produto exportado, e a necessidade crescente de diversificação da base.

Pelo contrário, para que ocorra crescimento constante North (1977b, p. 306) fala da necessidade do surgimento de "Industrias orientadas para as matérias-primas que, em razão das acentuadas vantagens de transferência do produto manufaturado sobre a matéria bruta, se localizam junto à fonte desta última", por tanto, sendo o sudeste do Pará uma região com grande reserva mineral para a indústria extrativa e área que está em crescente aumento da produtividade da agricultura e pecuária, mediante implantação de tecnologia. Possui a matériaprima necessária para implementar tais pressupostos. 
Ademais, o sudeste do Pará deixa de ser uma fronteira com frentes de expansão, por possuir um processo imigratório com diminuição das taxas apresentadas no passado, notadamente no período das políticas desenvolvimentistas (durante os governos militares). Ainda que exista o caráter de fronteira, a região está em processo de consolidação, no qual o uso cada vez mais frequente de tecnologia na agricultura, pecuária e mineração, tendem a aumentar a produtividade "A frente de expansão tornou-se, no fundo, o mundo residual da expansão capitalista, o que está além do território cujas terras podem ser apropriadas lucrativamente pelo capital" (MARTINS, 1996, p. 48). Apresentando-se como desafio, a internalização dos benefícios, através da geração de empregos formais e da distribuição de renda.

\section{Considerações Finais}

O sudeste do Pará teve na economia da borracha, a primeira atividade que modificou as relações de trabalho da região, ainda que em caráter precário, já adaptada ao atendimento de demandas exógenas à região, a comercialização da produção era controlada por financiadores da capital do estado e, em última instância, por grupos estrangeiros, e acabavam por apropriarse da maior parte da mais-valia gerada.

O passo determinante para a mudança de uma economia que se desenvolvia por forças locacionais para modelos concretos de polos, foram os programas governamentais que culminaram com a intensa atividade de exploração extrativista mineral e o agronegócio, suas relações modernas em termos de tecnologia, não refletiam novas relações de trabalho.

A base exportadora, desde que propicie o aparecimento de novos produtos de exportação e que gere poupança interna, que naturalmente tende a transbordar para outros setores, gerando emprego e renda, garantindo um crescimento econômico constante, refletindo em melhorias sociais e fortalecimento das instituições, é o modelo que pode conduzir a região ao desenvolvimento.

A região é uma fronteira que teve um desenvolvimento histórico impulsionado por várias frentes de expansão, direcionadas para um viés das grandes empresas do setor da extração e do agronegócio, ainda que em muitos casos alicerçado em atividades extrativistas da borracha ou da castanha, estas nunca tiveram como foco a subsistência, mas sim, um grande vínculo com atividades voltadas para o suprimento de necessidades exógenas à região. 
Esse processo se altera, de forma, que a fronteira, está atualmente, em processo de consolidação, mantendo as premissas básicas das atividades econômicas desenvolvidas, que ainda geram pouca distribuição de renda. Mas com significativa diminuição de taxas imigratórias inter-regionais e expansão de atividades econômicas nas áreas já desmatadas e com aumento de produtividade via utilização de tecnologias.

Esse modelo de pouca agregação de valor ao produto regional resultou em um crescimento desordenado e concentrado em alguns municípios possuidores de reservas de matérias-primas, e esse, é o desafio que a região tem que enfrentar. As três teorias referenciadas no estudo trazem contribuições para entender como ocorre o desenvolvimento regional no sudeste do Pará, e sugestões de como harmonizar o crescimento econômico na região, equacionando questões locacionais e de centralidades, atuando para reverter as forças de polarização e otimizando as vantagens da base exportadora existente.

\section{Referências}

ALMEIDA, Rogério. Amazônia, Pará e o mundo das águas do Baixo Tocantins. Estudos Avançados, São Paulo, n. 68, v. 24, p. 291-298, 2010.

ALVES DE JESUS, Josias; SPINOLA, Noelio Dantaslé. Seis décadas da Teoria dos Polos de Crescimento. Revista de Desenvolvimento Econômico, Salvador, n. 32, v. 17, p. 935-952, 2015. Disponível em: https://revistas.unifacs.br/index.php/rde/article/view/4204/2850. Acesso em: $14 / 11 / 2018$.

BECKER, Bertha K. Amazônia: Geopolítica na vidada do III milênio. Garamond, Rio de Janeiro. 2009.

. Geopolítica da Amazônia. Estudos avançados. São Paulo, n. 53, v. 19, p. 71-86, 2005. Disponível em: http://www.revistas.usp.br/eav/article/view/10047. Acesso em: 14/07/2018.

BRITO, Eliseu Pereira. O papel de Palmas - TO na rede de integração regional. 260 f. Dissertação (Mestrado em Geografia) - Universidade Federal da Grande Dourados, Dourados, 2009.

CAVALCANTE, Luiz Ricardo Mattos Teixeira. Produção teórica em economia regional: uma proposta de sistematização. Revista brasileira de estudos regionais e urbanos. n. 1, v. 2, p. 9-32, 2008. Disponível em: https://www.revistaaber.org.br/rberu/article/view/12/65. Acesso em: 20/05/2019.

CHRISTALLER, Walter. Central Places in Southern Germany. Prentice Hall, New Jersey, 1966.

CONGILIO, Célia Regina; IKEDA, Joyce Cardoso Olímpio. A ditadura militar, expansão do capital e as lutas sociais no sudeste paraense. Lutas Sociais. São Paulo, n. 32, v. 18, p. 79-90, 2014. Disponível em: https://revistas.pucsp.br/index.php/Is/article/view/25693/0. Acesso em: $13 / 08 / 2019$. 
CORRÊA, Roberto Lobato. A periodização da rede urbana da Amazônia. Revista Brasileira de Geografia, n. 3, v. 49, p. 39-68, 1987.

DALLABRIDA, Valdir Roque. Teorias do Desenvolvimento: aproximações teóricas que tentam explicar as possibilidades e desafios quanto ao desenvolvimento de lugares, regiões, territórios ou países. Editora CRV, Curitiba, Brasil. 2017.

FARAGE, Eblin. A Fronteira e a Expansão Territorial no Brasil: Resistência, Lutas e Massacres. Revista Em Pauta, n. 24, v. 6, p. 318-321, 2009.

FERREIRA, Carlos Maurício de Carvalho. Teoria dos Polos de Desenvolvimento: A questão da regionalização e os planos de desenvolvimento integrado dos vales das bacias hidrográficas amazônicas. CEDEPLAR/UFMG, Texto para Discussão n 63, Belo Horizonte, 1991. Disponível em: http://www.cedeplar.ufmg.br/pesquisas/td/TD\%2063.pdf. Acesso em: 09/08/2019.

GARRIDO FILHA; Irene; COSTA, Irio Barbosa da; RIBEIRO, Glória Vanicore. Estudo da Área Mineradora de Carajás. Revista Brasileira de Geografia, n. 4, v. 50, p. 105-163 1988.

FURTADO, Celso. Formação Econômica do Brasil. Companhia Editora Nacional, São Paulo, 2005.

KOHLHEPP, Gerd. Conflitos de interesse no ordenamento territorial da Amazônia brasileira. Estudos avançados, n. 45, v. 16, p. 37-61. 2002.

LIMA, Ana Carolina da Cruz; SIMÕES, Rodrigo Ferreira. Teorias clássicas do desenvolvimento regional e suas implicações de política econômica: o caso do Brasil. RDE-Revista de Desenvolvimento Econômico. n. 21, v. 12, 2010. Disponível em: http://www.revistas.unifacs.br/index.php/rde/article/view/878/940. Acesso em: 09/08/2019.

LINS, Andréia do Egito; LIMA, João Policarpo Rodrigues; GATTO, Maria Fernanda. Uma aplicação da teoria da base exportadora ao caso nordestino. Revista Econômica do Nordeste, $\mathrm{n}$. 1, v. 43, p. 9-32, 2012. Disponível em: https://ren.emnuvens.com.br/ren/article/view/205/183. Acesso em: 17/11/2018.

LOPES, Antônio Simões. Desenvolvimento Regional: Problemática, Teoria, Modelos. Fundação Calouste Gulbenkian, Lisboa, Portugal. 1984.

MADUREIRA, Eduardo Miguel Prata. Desenvolvimento regional: principais teorias. Revista Thêma et Scientia, n. 2, v. 5 p. 8-23, 2015. Disponível em:

https://www.fag.edu.br/upload/arquivo/1457726705.pdf. Acesso em: 12/08/2019.

MARTINS, José de Souza. Fronteira: a degradação do outro nos confins do humano. Editora HUCITEC, São Paulo, Brasil. 2009.

O tempo da Fronteira. Retorno à controvérsia sobre o temo histórico da frente de expansão e da frente pioneira. Tempo social, n. 1, v. 8, p. 25-70, 1996. Disponível em: https://www.revistas.usp.br/ts/article/view/86141. Acesso em: 29/08/2019.

MELLO, Neli Aparecida de; THERY, Hervé. A armadura do espaço amazônico: eixos e zoneamentos. Alceu, n. 2, v. 1, p. 181-214, 2001.

MOURA, José Mauro Sousa; PELEJA, José Reinaldo Pacheco; FARIA, Dóris Santos de. Módulo Interdisciplinar: estudos integrativos da Amazônia (EIA). Universidade Federal do Oeste do Pará, Santarém, Brasil, 2011. Disponível em: www.ufopa.edu.br/cfi/download/textos-domodulos/eia/at download/file. Acesso em: 31/08/2018. 
NORTH, Douglass C. A agricultura no crescimento econômico. In: SCHWARTZMAN, J. (Org.). Economia regional: textos escolhidos, Cedeplar, Cetrede, Minter, p. 333-343, 1977a.

Teoria da localização e crescimento econômico regional. In: Schwartzman, J. (Org). Economia regional: textos escolhidos, Cedeplar, Cetrede, Minter, p. 291-314, 1977a. Disponível em: http://www.ifibe.edu.br/arq/20150824222519320995672.pdf. Acesso em: 20/07/2019.

. Location theory and regional economic growth. Journal of political economy, n. 3, v. 63, p. 243-258, 1955.

OLIVEIRA, Gilson Batista de. LIMA, José Edmilson de Souza. Elementos endógenos do desenvolvimento regional: considerações sobre o papel da sociedade local no processo de desenvolvimento sustentável. Revista da FAE, n. 2, v. 6, p. 29-37, 2003. Disponível em: https://revistafae.fae.edu/revistafae/article/view/462/357. Acesso em: 01/06/2019.

OLIVEIRA, Nilton Marques de. Desenvolvimento Regional do Território do Estado do Tocantins: Implicações e Alternativas. Tese de Doutorado, Universidade Estadual do Oeste do Paraná, Toledo, Brasil, 2015.

OLIVEIRA, Nilton Marques de; CRESTANI, Leandro de Araújo; STRASSBURG, Udo. Fronteira Agrícola e Povoamento do Norte do Paraná: Uma Breve Consideração Histórico-Econômica. In: Leandro de Araújo Crestani, Leandro Baller; Nilton Marques de Oliveira (Org.), História, Fronteiras e Territórios: A Construção do Espaço Agrário. Fasul, Toledo, p. 37-53, 2016. Disponível em:

https://www.researchgate.net/publication/311512324 Historia Fronteiras e Territorios a co nstrucao do espaco agrario. Acesso em: 29/04/2019.

OLIVEIRA, Thiago José Arruda (2017). As transformações da base econômica nos municípios do Centro Norte BR (2000-2015). Tese de Doutorado, Universidade Estadual do Oeste do Paraná, Toledo, Brasil, 2017.

PALHETA, João Márcio et al. Conflitos Pelo Uso do Território na Amazônia Mineral. Mercator, v. 16, p. 1-18, 2017.

PARENTE, Temis Gomes. Fundamentos históricos do Estado do Tocantins, Editora da UFG, Goiânia, Brasil. 2003.

PERROUX, François. A Economia do século XX. Porto: Herder, 1967.

PIFFER, Moacir. A Teoria da Base Econômica e o Desenvolvimento Regional do Estado do Paraná no Final do Século XX. Tese de Doutorado, Universidade de Santa Cruz do Sul, 2009. Disponível em: https://repositorio.unisc.br/ispui/handle/11624/676. Acesso em: 31/08/2019.

RODRIGUES, Renan Albuquerque; TRINDADE, Deilson do Carmo; BITENCOURT, Mirian Souza. Trabalhadores na produção da essência de pau-rosa na Amazônia. Novos Cadernos NAEA, n. 2, v. 19, p. 173-191, 2016. Disponível em:

https://periodicos.ufpa.br/index.php/ncn/article/viewFile/2197/3920. Acesso em: 28/08/2019.

ROSTOW, Walt Whitman. Teoria do Desenvolvimento Econômico, Zahar, Rio de Janeiro, Brasil. 1974.

SANTOS, Roberto Araújo de Oliveira. História econômica da Amazônia: (1800-1920). T.A

Queiroz, São Paulo, Brasil, 1980. Disponível em:

https://achistorico.blogspot.com/2016/10/historia-economica-da-amazonia-1800-1920.html.

Acesso em: 04/08/2019. 
SANTOS, Valdeci Monteiro. A Economia do Sudeste Paraense: evidências das transformações estruturais. In: Aristides Monteiro Neto, César Nunes de Castro, Carlos Antônio Brandão (Org.).

Desenvolvimento Regional no Brasil: políticas, estratégias e perspectivas, IPEA, Rio de Janeiro, p. 127-155, 2017. Disponível

em:http://www.ipea.gov.br/portal/images/stories/PDFs/livros/livros/20170213 livro desenvol vimentoregional.pdf. Acesso em: 18/08/2019.

SPOSITO, Maria Encarnação Beltrão; ELIAS, Denise; SOARES, Beatriz Ribeiro. Agentes econômicos e reestruturação urbana e regional: Marabá e Los Ángeles. Editora Cultura Acadêmica, São Paulo, Brasil. 2016.

SCHWARTZMAN, Jacques. Outras teorias de desenvolvimento regional. In: Schwartzman, J. (Org.) Economia Regional: textos escolhidos, CEDEPLAR, Belo Horizonte, p. 235-239. 1977.

TAVARES, Maria Goretti da Costa. A Formação Territorial do Espaço Paraense: dos fortes à criação de municípios. ACTA Geográfica, n. 2, v. 2, p. 59-83, 2010. Disponível em:

https://revista.ufrr.br/actageo/article/view/204. Acesso em: 12/08/2019.

TOJAL, Marcyette Caldas; RICCI, Fábio. Manifestações Culturais e Econômicas na Microrregião de Marabá Contribuindo com o Desenvolvimento Regional. XIII Encontro Latino Americano de Iniciação Científica e IX Encontro Latino Americano de Pós-Graduação, Anais..., Universidade do Vale do Paraíba, João Pessoa, Brasil, 2009. Disponível em:

www.inicepg.univap.br/cd/INIC 2009/anais/arquivos/0588 1433 01.pdf. Acesso em: 13/07/2019.

TRINDADE JÚNIOR, Saint-Clair Cordeiro. Cidades e Centralidades na Amazônia: dos diferentes ordenamentos territoriais ao processo de urbanização difusa. Revista Cidades, n. 21, v. 12, p. 305-334, 2015. Disponível em:

http://revista.fct.unesp.br/index.php/revistacidades/article/viewFile/4872/3548. Acesso em: 06/08/2019.

VASCONCELLOS, Marco Antônio Sandoval. Economia: micro e macro, Atlas, São Paulo, Brasil. 2006

VASCONCELOS, Vitor Vieira. Portfólio Análise Espacial. Dissertação de Mestrado, Pontifícia Universidade Católica de Minas Gerais, Belo Horizonte, Brasil. 2009.

VELHO, Otávio Guilherme. Frentes de expansão e estrutura agrária: estudo do processo de penetração numa área da Transamazônica. Centro Edelstein de Pesquisas Sociais, Rio de Janeiro, Brasil, 2009.

VILLARINO, Leandro Vizin. A estrutura e o mercado: uma análise comparativa do Plano Trienal e do PAEG. Revista de Economia política, n. 2, v. 36, p. 372-388, 2016. Disponível em:

http://www.rep.org.br/PDF/143-7.PDF. Acesso em: 14/08/2019. 